\title{
Impedance spectroscopy characterization of an interdigital structure for continuous particle measurements in wood-driven heating systems
}

\author{
A. Weiss ${ }^{1}$, M. Bauer ${ }^{1}$, S. Eichenauer ${ }^{2}$, E. A. Stadlbauer ${ }^{2}$, and C.-D. Kohl ${ }^{1}$ \\ ${ }^{1}$ Institute of Applied Physics, JLU Giessen, Giessen, Germany \\ ${ }^{2}$ Competence Centre for Energy and Environmental Engineering, University of Applied Science THM, \\ Campus Giessen, Giessen, Germany
}

Correspondence to: A. Weiss (alexander.weiss@ap.physik.uni-giessen.de)

Received: 31 October 2014 - Revised: 31 December 2014 - Accepted: 8 January 2015 - Published: 5 February 2015

\begin{abstract}
In the course of the climate change and increased focus on $\mathrm{CO}_{2}$-neutral energy sources, the use of wood-driven small heating systems (SHS) becomes more important. But, their contribution to air pollution, especially particulate matter, is about as high as the emissions from car engines. The specific formation of harmful substances in wood fires and possible countermeasures by continuously operating sensor and control systems are covered.

Impedance spectra of interdigital electrode (IDE) structures are taken before and after mounting in wooddriven SHS to get information about the particles in the exhaust stream. It appears that the capacitive parts of the impedance spectra at a fixed frequency are appropriate for a fast signal evaluation. The good correlation with established offline measuring methods is discussed and the capability of thermal regeneration is demonstrated. The offline measurements of this work shall give the experimental basis for the development of online measurements in order to control the particle emissions of wood-driven SHS.
\end{abstract}

\section{Introduction}

The utilization of biomass for the generation of electricity and heat is becoming more important due to an increased focus on $\mathrm{CO}_{2}$-neutral energy sources. Particularly the sector of small heating systems (SHS) has a rising demand for wood as an alternative fuel. The denotation "small heating system" is often interpreted in different ways. In this paper, it refers to boilers, stoves and furnaces with a nominal power output of less than $50 \mathrm{~kW}$ that are typically used in residential and small industry or business buildings. It also explicitly includes the sector of single-room heating systems, e.g., closed fire places. In Germany, roughly half of the SHS are already wood-driven (approximately 15 million). Their number is growing steadily due to increasing prices of fossil fuels. Especially in rural areas with easy access to the regional forestry, wood is established as a cost-efficient fuel.

\subsection{Types of emissions}

This growing number of wood-driven SHS is accompanied by an additional load of emitted air pollutants. One of them that is worth focusing on is the fraction of particulate matter (PM), because it is considerably higher than that of comparable oil or gas burners. According to the German Federal Environmental Agency, it already exceeds the PM emission caused by engines (cars, trucks, motorcycles, etc.) in 2003 (GFEA, 2007). The importance of that problem is also underlined by the constitution of the promoting cluster ("emission reduction in biomass-driven SHS") by the German Federal Environment Foundation (GFEF, 2014).

Fine dust is categorized by its aerodynamic particle diameter in the classes $\mathrm{PM}_{10}(<10 \mu \mathrm{m}), \mathrm{PM}_{2.5}(<2.5 \mu \mathrm{m})$ and ultrafine dusts $(<0.1 \mu \mathrm{m})$. Besides this classification, which mainly provides information about the possibility of inhaling, the chemical nature of particles is also important for their effect on human health. Thereby, the primary aerosols 
are differentiated in soot, which mainly consists of carbon (black carbon, BC), mineral salts and condensable organic compounds (COC), also known as tars.

In addition, volatile organic compounds (VOC), ammonia, carbon monoxide and oxides of nitrogen build up during combustion. Besides their direct toxic impact, they also contribute to the secondary organic aerosols (SOA) as well as to the inorganic fraction by conversion processes in the atmosphere (Nussbaumer, 2010).

\subsection{Health effects}

The health risk of fine dust is primarily caused by its small particle sizes. While the human body has defense mechanisms against larger particles, fine dust is able to penetrate the lungs via the respiratory system. $\mathrm{PM}_{10}$ is named "inhalable", whereas $\mathrm{PM}_{2.5}$ is already classified as "respirable". Ultrafine dust is able to enter the alveoles (alveolar) and is hardly or even not at all removable. At this point, even in other respects, nontoxic substances can cause health damage like coughing, inflammation of the respiratory system, bronchitis or asthma.

Due to the large surface area of the pulmonary tissue, particles can also migrate to the blood and lead to serious diseases of the cardiovascular system (e.g., heart attack), especially for long time exposures. Long-term studies show that there is a correlation between elevated mortality rate, particularly by respiratory system diseases or lung cancer, and the fine dust pollution (LUA, 2005).

Klippel and Nussbaumer (2007a) showed that health effects of fine dust depend not only on its particle sizes but are also mainly influenced by its chemical composition. Accordingly, the weakest health effects are caused by dust that mostly consists of mineral salts, such as those occurring in well-adjusted combustion systems. Compared to that, the cell toxicity of organic dusts from incomplete combustion is approximately 100 times higher. Besides the soot fraction (BC), they include mostly condensable organic compounds (COC). Additionally, a large number of different polycyclic aromatic hydrocarbons (PAH) can be found that are well known for their high carcinogenic impact. An overview of the health effects of fine dust is given by Nussbaumer (2012).

\subsection{Legal framework}

The German 1st Federal Immission Protection Directive (1st BImSchV) regulates the operation and inspection of small- and medium-sized heating systems (GFRG, 2010). The need for a reduction in pollutants is reflected in stricter emission limits in the latest version of 22 March 2010. Table 1 shows the two-stage lowering of the maximum concentrations of $\mathrm{CO}$ and dust allowed. There are some interim arrangements for existing systems. If single-room heating systems do not fulfill the requirements of maximum allowed emission levels of $0.15 \mathrm{~g} \mathrm{~m}^{-3}$ dust and $4 \mathrm{~g} \mathrm{~m}^{-3} \mathrm{CO}$ in an in-
Table 1. Emission limits for small heating systems according to the 1st BImSchV (GFRG, 2010).

\begin{tabular}{|c|c|c|c|c|}
\hline & \multicolumn{2}{|c|}{ From 22 Mar 2010} & \multicolumn{2}{|c|}{$\begin{array}{l}\text { From } 31 \text { Dec } 2014 \\
\quad(31 \text { Dec 2016) }\end{array}$} \\
\hline & $\begin{array}{l}\mathrm{CO} \\
\left(\mathrm{g} \mathrm{m}^{-3}\right)\end{array}$ & $\begin{array}{l}\text { Dust } \\
\left(\mathrm{mg} \mathrm{m}^{-3}\right)\end{array}$ & $\begin{array}{l}\mathrm{CO} \\
\left(\mathrm{g} \mathrm{m}^{-3}\right)\end{array}$ & $\begin{array}{l}\text { Dust } \\
\left(\mathrm{mg} \mathrm{m}^{-3}\right)\end{array}$ \\
\hline $\begin{array}{l}\text { Single-room heating } \\
\text { system }\end{array}$ & $\begin{array}{l}2.0 \\
0.4^{b}\end{array}$ & $\begin{array}{l}75 \\
30-50^{b}\end{array}$ & $\begin{array}{l}1.25 \\
0.25^{b}\end{array}$ & $\begin{array}{l}40 \\
20-30^{b}\end{array}$ \\
\hline $\begin{array}{l}\text { SHS }>4 \mathrm{~kW} \text { driven } \\
\text { with natural wood }\end{array}$ & $\begin{array}{l}0.8^{\mathrm{a}} \\
0.5^{\mathrm{b}}\end{array}$ & $\begin{array}{l}100^{\mathrm{a}} \\
60^{\mathrm{b}}\end{array}$ & 0.5 & 20 \\
\hline
\end{tabular}

spection, they have to be upgraded or put out of operation between 2014 and 2024, depending on the year of installation.

Currently, the 1st BImSchV does not define limits for the emission of nitrogen oxides $\left(\mathrm{NO}_{\mathrm{x}}\right)$ from wood-driven SHS. $\mathrm{NO}_{\mathrm{x}}$ regulations only exist for oil- and gas-driven SHS as well as for fuels with high nitrogen content like straw and grain. However, the DINplus seal of quality already limits the $\mathrm{NO}_{\mathrm{x}}$ emission of wood-driven SHS to $200 \mathrm{mg} \mathrm{Nm}^{-3}$, underlining their increasing relevance.

\section{Characteristics of wood combustion}

\subsection{Properties of wood}

Wood consists for the most part of cellulose and hemicellulose (60-80\% of the dry mass). These polysaccharides give tensile strength to the wood by its fibrillae. The phenolic macro-molecule lignin contributes about $30 \%$ of the dry mass. It exhibits molecule masses in the range of 5000 to $10000 \mathrm{u}$ and, in contrast to the weak parts of the plant, it gives compression strength to the wood. In addition, there are some extractives like resins or minerals. The exact composition differs depending on the type of wood and individual growing conditions.

Besides these constituents, forming the dry mass, a considerable amount of water is present in wood. The wood moisture, which is defined as the ratio of water mass to the wood dry mass, can measure up to $150 \%$ for fresh chopped trunks. During drying it is reduced, depending on the ambient conditions. Wood moisture is an important parameter for combustion, because it reduces the lower heating value (LHV) by its evaporation during combustion.

\subsection{Combustion}

According to Nussbaumer (2010), the combustion of wood can be generally divided into three phases. In the first phase, the wood is dried, causing the residual wood moisture to evaporate. Afterwards, gasification and pyrolysis begin, at which point volatile hydrocarbons are released into the gas phase and carbonaceous organic compounds (cel- 
lulose, hemicellulose and lignin) start to decompose. Coke, volatile compounds ( $\mathrm{CO}, \mathrm{H}_{2}$ and VOC) and condensible organic compounds (COC) originate from this decomposition process. Under optimal conditions, these products are oxidized to $\mathrm{CO}_{2}$ and $\mathrm{H}_{2} \mathrm{O}$ in the third phase (Nussbaumer, 2010). Concerning the whole fuel volume, it is important to notice that all three phases take place at the same time. While oxidation takes place at one point of the wood, it influences drying and pyrolysis at another point of it.

\subsection{Formation of pollutants}

\subsubsection{Dust}

During combustion with a restricted oxygen supply, particles form from incompletely burned components. At high temperatures $\left(>800^{\circ} \mathrm{C}\right)$, the organic compounds are decomposed to a degree at which mainly carbonic soot (black carbon, BC) is generated. On the other hand, if the temperature of the fire is low, mainly COC arise, because the already formed tars cannot react any further and condense to particles in the atmosphere. Low fire temperatures can occur for different reasons, e.g., energy consumed by evaporation of high moisture content, retarded exothermal oxidation due to oxygen deficiency, or due to cooling by an excessive inlet air stream (Nussbaumer, 2010). In fact, VOC also contribute to the organic aerosols, but their conversion to particles takes place by secondary reaction in the atmosphere (secondary organic aerosols, SOA). In this process, the mass of the particles can exceed the original mass of VOC by a factor of 2 , due to the uptake of further elements (Nussbaumer, 2010).

In contrast to the organic fraction, the emission of mineral components can also occur in complete combustion. They form either by evaporation and subsequent condensation in the cooling phase or are carried away from the ashes by the exhaust stream. They mainly consist of chlorides, sulfates, carbonites and oxides of the alkaline metal and alkaline earth metals (Oser et al., 2003).

\subsubsection{Oxides of nitrogen}

In contrast to other kinds of combustion systems, the temperatures in wood-driven SHS are low enough that the formation of $\mathrm{NO}_{\mathrm{x}}$ from the atmospheric nitrogen (thermal $\mathrm{NO}_{\mathrm{x}}$ ) can be neglected. In this case, the nitrogen originates from the wood itself (fuel $\mathrm{NO}_{\mathrm{x}}$ ), where its content is significantly higher than in fossil fuels. However, the effectively emitted amount of $\mathrm{NO}_{\mathrm{x}}$ can be considerably reduced by low- $\mathrm{NO}_{\mathrm{x}}$ methods like fuel or air staging. The latter is characterized by the spatial separation of supply air into primary and secondary air. Thereby, the primary air area has to be highly substoichiometric to generate an oxygen-deficient reduction zone. Nitrogen-containing compounds can be reduced to molecular nitrogen at high temperatures (approximately $1100^{\circ} \mathrm{C}$ ) combined with a dwell time of at least $0.5 \mathrm{~s}$ in this zone. The complete oxidation of the organic parts is carried out by the subsequent addition of secondary air (Hasler et al., 2000). A distinctive reduction zone $(0.2<\lambda<0.3)$ also favors lower emissions of particulate matter.

\subsection{Mode of operation and sensor-controlled operation}

A consequence of varying fuel properties (wood moisture, loading of the combustion chamber, etc.) and the complex relationships between the operating parameters is a discontinuous combustion with partly high emissions. Hence, the accepted opinion in research and in the chimney sweeper trade is that the typical mode of operation of wood-driven SHS is far away from the optimum. Thus, in general, the actual emissions significantly exceed the values measured under norm conditions. This supports the assumption that the fraction of wood-fired heating as a source of fine dust is considerably underestimated (Nussbaumer, 2010). Studies in a German residential area show that wood-fired heating is responsible for up to $57 \%$ of the ambient $\mathrm{PM}_{10}$ pollution under certain weather conditions (Bari et al., 2011).

Therefore, it is reasonable to adjust the available variables like primary air, secondary air and fuel supply to the current combustion conditions to achieve minimum emissions. To evaluate these conditions, a control system needs comprehensive sensor technology for the direct measurement of all relevant emission quantities. Similar approaches for smallscale biomass furnaces were recently investigated by Bischof et al. (2013).

\section{Sensors}

\subsection{Systems currently in use}

In contrast to large combustion systems or to the control of combustion engines (lambda probe), continuously working sensor systems are not common in wood-driven SHS. If continuous systems are present anyway, it is mostly about temperature-sensitive elements for power management. These can either mechanically control (bimetal, thermostat) the inlet air, causing bad combustion conditions, or regulate the fuel amount, e.g., in modern pellet combustion systems. Besides a measurement of the boiler temperature in water-bearing systems, there is the possibility of placing thermo-elements directly in the combustion chamber. In some rare cases, lambda probes are used to gauge the needed amount of inlet air. In contrast to combustion engines, which usually work in a narrow range around the stoichiometric mixture $(0.9<\lambda<1.1)$, there are lower values in the reduction zone $(0.2<\lambda<0.7)$ and higher ones in the oxidation zone $(1.4<\lambda)$.

The sensor systems currently in use with regard to SHS refer to the measurements observing emission limits that are regulated by law. In contrast to continuously working sensor systems, these kinds of snap sample measurements are not applicable for electronic combustion control. They 


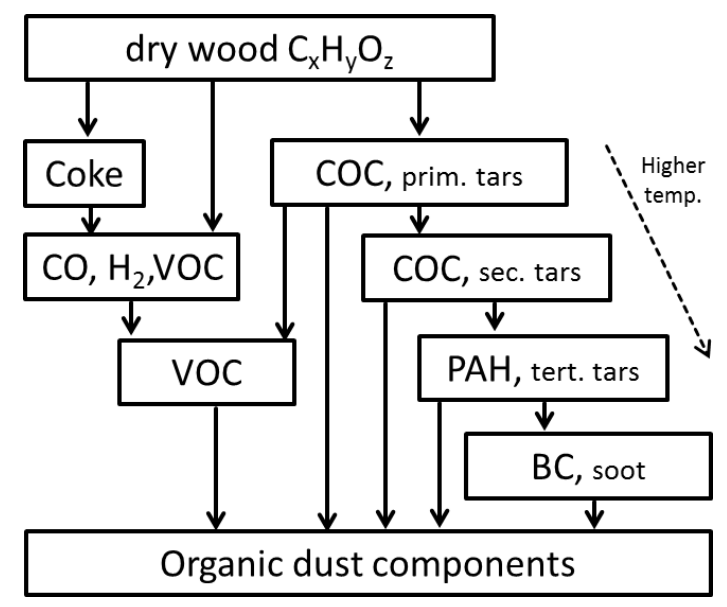

Figure 1. Ways of conversion of the hydrocarbons to organic dust components according to Nussbaumer (2010) (Weiss et al., 2014).

are only suitable for the detection of leakages or maladjustments. These $15 \mathrm{~min}$ measurements are performed by chimney sweepers and serve for observation of the limits of dust and CO. Additionally, the temperature, oxygen content and pressure difference is taken to benchmark the operating status.

Measurement methods regarding PM include mainly gravimetric ones, but optical (scattered light, photoemission) and electrostatic methods are in use, too. The gravimetric methods feature, e.g., filter cartridges that are weighed after sampling or are part of a resonance circuit. The gaseous measurands $\left(\mathrm{CO}, \mathrm{O}_{2}\right.$ and $\left.\mathrm{NO}_{\mathrm{x}}\right)$ are taken by electrochemical cells in some instruments. The temperature can be measured by thermocouples (e.g., by type K).

The instruments that are compliant for measurements according to 1 st $\mathrm{BImSchV}$ exhibit a measurement uncertainty of 30 to $50 \%$ concerning the dust content. Furthermore, the costs of EUR 5000 to EUR 20000 per instrument are a high investment for the user.

\subsection{Sensors for continuous measurements}

To use sensors for the control of SHS operating parameters, the measurement method has to work continuously and must withstand the rough conditions in combustion systems by its technical implementation. Low costs per unit are essential for an economical realization.

In the field of gas sensing, metal oxide gas sensors (MOX) are suitable for this challenge. For example, tin oxide sensors for the measurement of $\mathrm{CO}$ have already been developed for fire detection in lignite-fired power plants. Despite the rough ambient conditions (particularly dust), they achieve lifetimes of up to 7 years and have been applied successfully in many power plants (Kohl et al., 2001). Also, the $\mathrm{NO}_{\mathrm{x}}$ measurement can be carried out by MOX. Benner et al. (2002) showed that the used MOX withstand the combustion chamber conditions

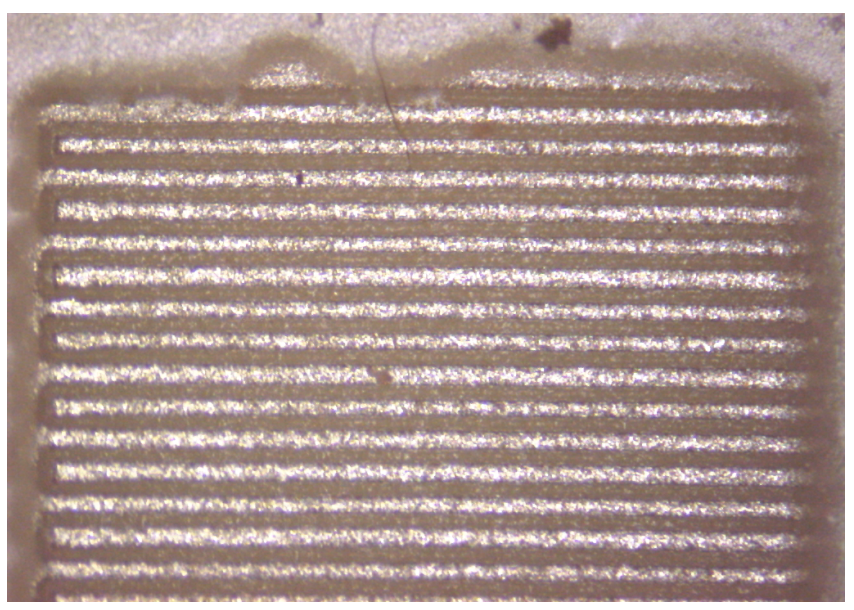

Figure 2. Used IDE structure consisting of a ceramic substrate $\left(\mathrm{Al}_{2} \mathrm{O}_{3}\right)$ and platinum interdigital electrodes. The electrode width and distance is $27.5 \mu \mathrm{m}$, the length $1400 \mu \mathrm{m}$ and the number of legs 34 (Weiss et al., 2014).

of a power plant at up to $650^{\circ} \mathrm{C}$. Electrochemical sensors cannot be operated under these conditions. They are only suitable in bypass measurements at lower temperatures after exhaust stream cooling. Their lifetime is typically on the order of 1 to 3 years and thereby shorter than that of MOX.

Direct measurement of the dust emission is crucial for controlled operation, because it cannot be determined just by the knowledge of other measurands like the $\mathrm{CO}$ concentration due to the fact that there is no clear correlation (Klippel and Nussbaumer, 2007b). For this task, common quartz bulk oscillators (QCM) are not suitable, because the limited temperature stability of quartz does not allow thermal regeneration. But, other piezoelectric materials like langasite may also be candidates for high temperature application (Richter et al., 2008; Richter and Fritze, 2014). Surface acoustic wave devices are commonly used as sensors in various applications, especially for the detection of mass deposits on its surface. But, under rough and fluctuating conditions - like those present in SHS - they are hard to operate. Because temperature deviations of only $1 \mathrm{~K}$ can be enough to interfere with the pure sensor response, temperature compensation, e.g., by a dual-port SAW, is necessary (Mujahid and Dickert, 2014). Beyond that, the elastic and conductance properties can spoil the result by a factor of up to 2 . Our own approach for a capacitive dust measurement procedure will be detailed in the following section.

\section{Capacitive dust measurement}

An approach for dust measurements in wood-driven SHS was investigated by the authors in a joint research project with partners from industry and a chimney sweep academy. The basis of the measurement is a ceramic substrate $\left(\mathrm{Al}_{2} \mathrm{O}_{3}\right)$ with platinum interdigital electrodes (IDE); cf. Fig. 2. Compara- 
ble structures as resistive-type dust sensors are also in use for the monitoring of particulate filters in automotive applications (Bosch, Continental) and are currently under investigation (Bartscherer and Moos, 2013). Recently, they have been suggested for the detection of conductive smoke deposits in electrical installations (Cleary, 2014). Resistance measurements of such structures require a minimum level of coverage at which the percolation threshold is reached and a conducting path builds up. The disadvantages are that low levels of coverage cannot be determined and that only conducting particles contribute to the signal.

In contrast to the detection of filter damages in cars, where the relevant timescale is on the order of hours or days, a sensor for the control of wood combustion has to operate on scales of less than a minute. Quick reaction and the detection of small amounts of dust are crucial for the application. Therefore, a capacitive approach is deployed. Dust deposited on and between the electrodes gives rise to the capacitance of the device by its permeability even when no conduction path develops.

\subsection{Technical realization}

To design simple electronics for a capacitive online measurement, it is first necessary to analyze the IDE structure and dust properties in detail. Therefore, in contrast to the future application, in this proof of principle, all measurements were conducted in the lab of the university, not online in SHS. Thus, the fresh IDE structures were first investigated by impedance spectroscopy (IS), subsequently loaded with dust in SHS and afterwards characterized by IS again. Impedance spectra were taken using a Solartron SI1260 in combination with a Chelsea dielectric interface that facilitates the measurement of small currents and therefore extends the measuring range to small capacitances even at low frequencies. The complex capacitance $C^{*}$ is calculated from the complex impedance $Z^{*}$ according to Eq. (1).

$C^{*}=\frac{Y^{*}}{i \cdot \omega}=\frac{1}{i \cdot \omega \cdot Z^{*}}$

$\operatorname{Re}(C)=\frac{-\operatorname{Im}(Z)}{\omega\left(\operatorname{Re}(Z)^{2}+\operatorname{Im}(Z)^{2}\right)}$.

The real part of $C^{*}$ is expressed by Eq. (2) and describes the capacitance of a capacitor in an equivalent circuit model that is frequency independent for an ideal capacitor-like system. The IDE exhibits only minor frequency dependency in the range from 1 to $10^{5} \mathrm{~Hz}(<0.5 \%)$. Thus, the sensor response $C / C_{0}$ for low (no conducting) coverage can easily be calculated by using one frequency $(16.3 \mathrm{kHz})$, which is important for future device implementations.

The measured base capacitance $C_{0}$ (without dust load, at room temperature) of the IDEs is in the range from 2.5 to $2.9 \mathrm{pF}$ due to minor production fluctuations. A theoretical description of such a system is given by Endres and

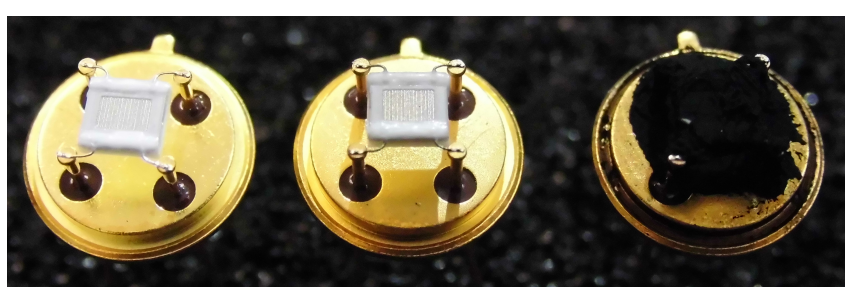

Figure 3. Socket mounted IDE structures. Left: fresh; middle: light loaded (response $\sim 3 \%$ ); right: heavily loaded (response $419 \%$, percolation threshold exceeded) (Weiss et al., 2014).

Drost (1991) and Endres and Bock (2006), and results in Eq. (3):

$C=(n-1) \cdot L \cdot \varepsilon_{0} \cdot\left(\left(\frac{\varepsilon_{L}+\varepsilon_{S}}{2}\right) \cdot \frac{K \cdot\left(\sqrt{1-\left(\frac{a}{a+b}\right)^{2}}\right)}{K \cdot\left(\frac{a}{a+b}\right)^{2}}+\varepsilon_{L} \frac{h}{a}\right)$,

where $a, b, h, L$ and $n$ are electrode distance, width, height, length and number, respectively, $\varepsilon_{L}$ and $\varepsilon_{S}$ are the relative permittivities of air and substrate material and $K(x)$ is the elliptic integral of the first kind (Endres and Drost, 1991; Endres and Bock, 2006). Taking average values of the used IDE ( $a=27.5 \mu \mathrm{m}, b=27.5 \mu \mathrm{m}, h=5 \mu \mathrm{m}, L=1400 \mu \mathrm{m}, n=34$, $\left.\varepsilon_{L}=1.000059, \varepsilon_{S}=9.5\right)$, Eq. (3) yields a capacitance of $2.9 \mathrm{pF}$, which is in good agreement with our results. In principle, electrode distances will not affect the results in resistive measurements (assuming a homogeneous coverage with sufficiently small particles). In a capacitive approach, it will influence the base capacitance $\left(C_{0}\right)$ as well as the sensitivity. Therefore, an adjustment of the electrode structure can be utilized as an optimization parameter in further investigations.

The capacitance shows only small fluctuations between measurements from day to day $(0.04 \%)$ in the laboratory setup. Signal changes of $0.1 \%$ can be clearly separated from the noise. The cross-sensitivity to humidity is quite low. The capacitance of the fresh IDE structure at $16.3 \mathrm{kHz}$ changes by only $0.03 \%$, when the relative humidity is varied from 0 to $30 \%$ at room temperature. Figure 3 shows examples of three IDE structures with different levels of soot loading from a wood-driven SHS. As can be seen, even hardly visible loadings lead to clearly measurable results (middle). The response will reach very high values for loads in excess of the percolation threshold (right).

\subsection{Thermal regeneration}

Besides IDE, the substrate possesses a platinum resistance wire (PT10) that is arranged in a U shape around the IDE in a sublayer and that serves as a resistance thermometer and heating. It allows an exact temperature control as well as thermal regeneration at temperatures up to $800^{\circ} \mathrm{C}$. The organic part of the dust deposits can be burned directly on the IDE structure. Optical investigations reveal that $650^{\circ} \mathrm{C}$ 


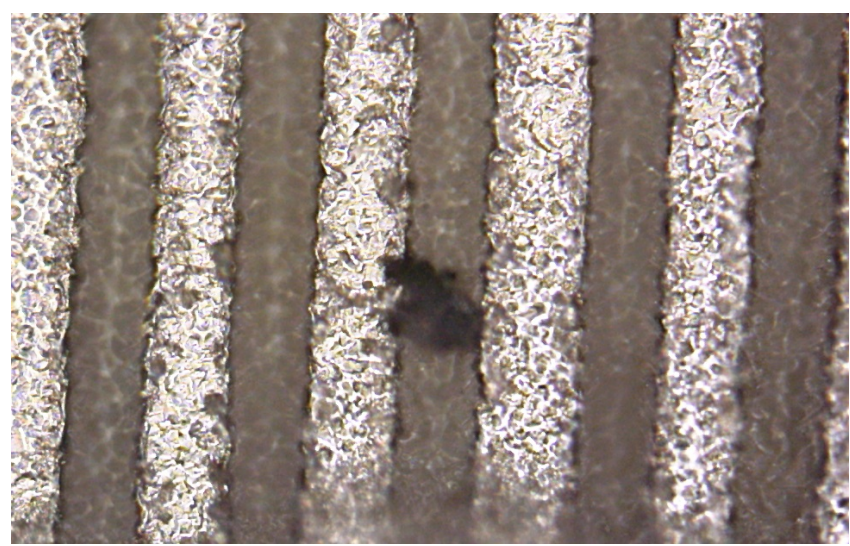

Figure 4. Single soot particle left between the platinum electrodes after a first regeneration step. The particle was removed by a second regeneration (electrode width $27.5 \mu \mathrm{m}$ ).

are sufficient to relieve the surface of all black deposits. The required time depends on the amount of dust and varies between a few seconds for light loading and up to $5 \mathrm{~min}$ for heavy loading. Higher temperatures are able to fasten this procedure. In a series of ten regeneration tests, only one sensor showed a single residual soot particle after a first regeneration step (see Fig. 4). A second regeneration was sufficient to remove the particle. The complete cleaning of the sensor surface is verified by further IS measurements. It is shown that the capacitance returned to its former basic value of $C_{0}$.

The dissipated heating power during temperaturecontrolled regeneration can serve as a further measurand. As indicated in Fig. 5, higher dust loadings require an elevated amount of heat. This optional analysis step may deliver additional information about the dust loading and will be the object of further investigations, as well as the detailed temperature dependence of the IDE structure.

\subsection{Results from the test grid}

Series of measurements were performed with IDE structures loaded in different SHS (Buderus Blueline stove, Buderus Logano S231-25 wood gasifier) and with different kinds of wood-based fuels. In each case, the IDE structures are placed in the exhaust tube directly behind the SHS with the surface facing upstream in the direction of the combustion chamber. Because it is not possible to generate completely reproducible combustion situations (see Sect. 2), reference systems are necessary. The only feasible ones are the instruments according to 1 st $\mathrm{BImSchV}$ and in accordance with VDI guideline 2066-1 from which two with different measurement principles are used. Due to the fact that they are not designed for continuous operation, they enforce $15 \mathrm{~min}$ measurements with corresponding high loading levels for the IDE sensor.

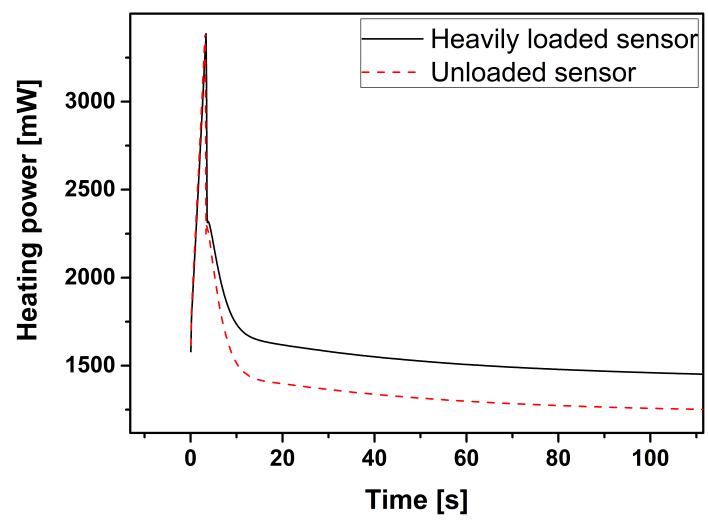

Figure 5. Dissipated heating power during thermal regeneration of a heavily loaded IDE structure (line) and a fresh IDE structure (dashed line).

First results indicated that there is an acceptable correlation between the IDE sensor and references despite the fact that the capacitance signal is not volume weighted like the references (Weiss et al., 2014).

Further results from a series with four different woodbased fuels using the Buderus Blueline stove are shown in Fig. 6. The measurement numbers indicate eight separate fires. To evaluate the relative accuracy of the IDE sensors, each measurement is carried out using two of them in parallel. As can be seen, the relative deviations are small, with only $6 \%$ of the response on average and some points so close to one another that they can hardly be differentiated on this scale. A distinguishable correlation between IDE sensor response and the reference values is achieved over all measurements, despite various fuels. The remarkable deviations of the two reference instruments (Fig. 6: nos. 5 to 8 ) may be caused by a saturation effect of reference instrument 1 due to the high dust concentrations $\left(>150 \mathrm{mg} \mathrm{m}^{-3}\right)$.

Measurement no. 8 exhibits an overestimation of the dust content by the IDE sensor. Detailed inspection of the trends of temperature, dust, $\mathrm{CO}$ and $\mathrm{O}_{2}$ reveals that the fire has come to the final combustion phase during the measurement. This has a strong influence on the pressure inside the systems and therefore on the exhaust velocity. In contrast to the IDE sensor, the volume-weighted values of the reference instruments compensate for that effect, which may explain the deviation.

\section{Conclusions}

The continuous in situ measurement of particles under firing conditions is an important task to reduce wood fire emissions, especially during the initial and ceasing states. This paper presents a first step in that direction, showing that cheap interdigital structures generate useful signals for an economical device. Further on, it could be shown that these devices can be used repeatedly in a cyclic manner. That opens the 

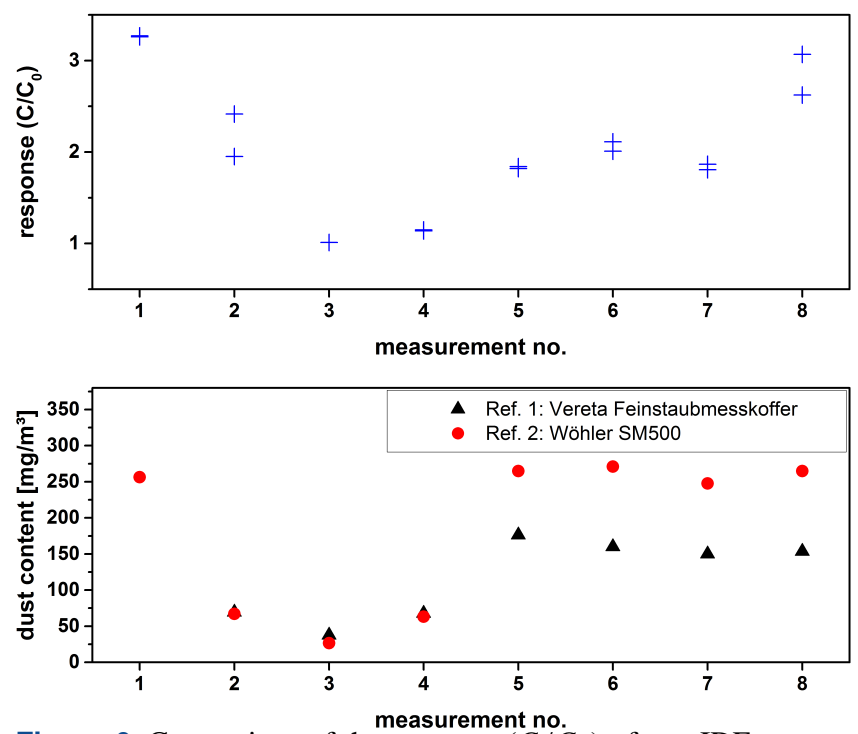

Figure 6. Comparison of the response $\left(C / C_{0}\right)$ of two IDE sensors at a frequency of $16.3 \mathrm{kHz}$ with values from two reference instruments. The response of both IDE sensors overlap at several points due to their small deviation. The fuels are HTC char (no. 1, no. 2), beech briquette (no. 3, no. 4), Pini\&Kay briquette beech (no. 5, no. 6), Pini\&Kay briquette spruce (no. 7, no. 8). The deposition time is 15 min according to the $1 \mathrm{st} \mathrm{BImSchV}$ requirements of the reference instruments.

possibility of applying them in an online control system for wood-driven SHS.

At this early stage of research, the sensors already show a good correlation with reference instruments in offline measurements, although the data analysis of the IDE sensor presented here is not explicitly dedicated to dust loadings beyond the percolation threshold. But, such high loading levels were reached in the measurements due to the $15 \mathrm{~min}$ time interval according to 1 st $\mathrm{BImSchV}$, which is necessary for the reference instruments. Furthermore, a large optimization potential can be utilized by taking the actual exhaust stream velocity into consideration by measuring or controlling it in ways of geometrical flow dynamic manipulation. Also, the electrode structure can be further adapted to the main particle properties.

The influence of humidity on the capacitance of loaded sensors should be part of comprehensive studies. The varying chemical composition and morphology of the particles may lead to different effects due to the environmental dependency of the water permittivity. It can drop by a factor of approximately 8 in close vicinity to surfaces (Paul and Paddison, 2001). Comparative investigations with other methods like differential thermal analysis are expedient.

First tests of capacitive sensor readout with simpler electronics are conducted under lab conditions with promising results. As mentioned above, the dissipated heating power as another measurand as well as the thermal dependence of the permittivity will be part of further investigation.
Acknowledgements. The authors thank Bernd Vollmer and Hans-Eberhard Kopp of the North Rhine-Westphalia chimney sweep academy (Schornsteinfegerakademie Dülmen) as well as Ulrich Strohal and Jochen Fey of the Strohal enterprise (Strohal Anlagenbau, Staufenberg) for their technical support and preparation of the test combustion systems. Further gratitude goes to the German Federal Environment Foundation for supporting the project.

Edited by: A. Schütze

Reviewed by: two anonymous referees

\section{References}

Bari, M. A., Baumbach, G., Kuch, B., and Scheffknecht, G.: Air pollution in residential areas from wood-fired heating, Aerosol Air Qual. Res., 11, 749-757, 2011.

Bartscherer, P. and Moos, R.: Improvement of the sensitivity of a conductometric soot sensor by adding a conductive cover layer, J. Sens. Sens. Syst., 2, 95-102, doi:10.5194/jsss-2-95-2013, 2013.

Benner, N., Eberheim, A., and Kohl, D.: Halbleiter-Gassensoren in der Rauchgasanalyse, 11. ITG/GMA Fachtagung Sensoren und Messsysteme, Ludwigsburg, 2002.

Bischof, J., Baumbach, G., and Struschka, M.: A new approach for CO-based control of small-scale biomass furnaces, Proceedings of the 21st European Biomass Conference and Exhibtion, Copenhagen, Denmark, 3-7 June 2013.

Cleary, T.: Effects of Soot Deposition on Current Leakage in Electronic Circuitry, Proceedings of 14th International Conference on Automatic Fire Detection, 14-16 October 2014.

Endres, H.-E. and Bock, K.: Impedanzspektroskopie und multivariante Signalverarbeitung für planare chemische Sensoren, Technische Mitteilungen 1/2 06, ISSN 0040-1439, Essen, 2006.

Endres, H.-E. and Drost, S.: Optimization of the geometry of gassensitive interdigital capacitors, Sens. Act., B4, 95-98, 1991.

GFEA, German Federal Environmental Agency: Die Nebenwirkungen der Behaglichkeit: Feinstaub aus Kamin und Holzofen, Berlin 2007.

GFEF, German Federal Environment Foundation: Kleine Holzfeuerungsanlagen: Klimafreundlich heizen und Feinstaubbelastung senken, DBU-aktuell No. 1, 2014.

GFRG, Government of the Ferderal Republic Germany: Erste Verordnung zur Durchführung des BundesImmissionsschutzgesetzes (Verordnung über kleine und mittlere Feuerungsanlagen - 1st BImSchV), Berlin, 2010.

Hasler, P., Nussbaumer, T., and Jenni, A.: Praxiserhebung über Stickoxid- und Partikelemissionen automatischer Holzfeuerungen, Bundesamt für Energie BFE, Zürich, 2000.

Klippel, N. and Nussbaumer, T.: Health relevance of particles from wood combustion in comparison to diesel soot, 15th European Biomass Conference and Exhibition, Berlin, 7-11 Mai 2007a.

Klippel, N. and Nussbaumer, T.: Einfluss der Betriebsweise auf die Partikelemission von Holzöfen, Bundesamt für Energie BFE, ISBN 3-908705-15-0, Zürich, 2007b.

Kohl, D., Kelleter, J., and Petig, H.: Detection of Fires by Gas Sensors, Sensors Update, 9, 161-223, 2001.

LUA NRW, Landesumweltamt Nordrhein-Westfahlen, Fachberichte 7/2005, ISSN 1613-0715, Essen, 2005. 
Mujahid, A. and Dickert, F. L.: SAW and Functional Polymers, in Kohl, C.-D. and Wagner, T., Gas Sensing Fundamentals, Springer Series on Chemical Sensors and Biosensors, 15, 213246, doi:10.1007/5346_2013_55,2014.

Nussbaumer, T.: Emissionsfaktoren von Holzfeuerungen und Klimaeffekt von Aerosolen aus der Bio-masse-Verbrennung, 11. Holzenergie-Symposium, Zürich, 17 September 2010.

Nussbaumer, T.: Gesundheitsauswirkungen von Feinstaub aus Holzfeuerungen, 12. Holzenergie-Symposium, Zürich, 14 September 2012.

Oser, M., Nussbaumer, T., Mueller, P., Mohr, M., and Figi, R.: Final report of the research program 26688, Grundlagen der Aerosolbildung in Holzfeuerungen, Bundesamt für Energie BFE, ISBN 3-908705-02-9, doi:10.1109/ICSENS.2008.4716740, 2003.

Paul, R. and Paddison, S. J.: A statistical mechanical model for the calculation of the permittivity of water in hydrated polymer electrolyte membrane pores, J. Chem. Phys., 115, 7762-7771, 2001.
Richter, D., Sauerwald, J., Fritze, H., Ansorge, E., and Schmidt, B.: Miniaturized resonant gas sensor for high temperature applications, Proceedings of the 7th IEEE Conference on Sensors, Lecce, 1536-1539, 26-29 October 2008, doi:10.1109/ICSENS.2008.4716740, 2008.

Richter, D. and Fritze, H.: High temperature gas sensors, in: Gas Sensing Fundamentals, edited by: Kohl, C.-D. and Wagner, T., Springer Series on Chemical Sensors and Biosensors, 15, 1-16, doi:10.1007/5346_2013_56, 2014.

Weiss, A., Eichenauer, S., Stadlbauerm E. A., and Kohl, C.-D.: Sensor systems for the reduction of particulate matter in wood driven fire places, Proceedings of the 17th ITG/GMA symposium on sensors and measurement systems, Nuernberg, 3-4 June 2014. 